\title{
ÍNDICE E PERCENTUAL DE ÁREAS VERDES PARA O PERÍMETRO URBANO DE OURO
}

PRETO - MG

Thiago Nogueira Lucon ${ }^{1}$; José Francisco do Prado Filho²; Frederico Garcia Sobreira ${ }^{34}$.

\section{Resumo}

O forte crescimento populacional da cidade de Ouro Preto (MG) registrado principalmente a partir da década de oitenta, aliado à insistente falta de políticas públicas eficazes vem trazendo inúmeras conseqüências negativas para os seus moradores. Numa tentativa de reverter, ou de pelo menos minimizar estes efeitos, especialistas da área urbano-ambiental desenvolveram diversas ferramentas e estratégias: o cálculo do Percentual de Áreas verdes (PAV), o Índice de Áreas Verdes (IAV), dentre outros, a fim de auxiliar nas tomadas de decisões quanto ao planejamento e a recuperação ambiental do espaço urbano. Este estudo calculou a Densidade Populacional (DP), a Porcentagem de Áreas Verdes (PAV) e o Índice de Áreas Verdes (IAV), para cada setor censitário da cidade de Ouro Preto do IBGE, 2007, obtendo os seguintes resultados: dos 27,9 km2 que compõe o perímetro urbano, aproximadamente, 24\% (6,69 km2) se constituí de áreas construídas, e 76\% (21,09 km2) de áreas verdes. Os setores censitários mais populosos da cidade estão inseridos nos bairros Padre Faria, Morro Santana, Morro São João, Nossa Senhora das Dores e Vila Aparecida; os setores com Densidades Populacionais (DP) mais elevadas pertencem aos bairros Vila Itacolomi, Alto da Cruz e São Cristóvão; as Porcentagens de Áreas Verdes (PAV) mais baixas foram encontradas nos setores inseridos nos bairros São Cristóvão, Alto da Cruz e Vila Itacolomi e os piores valores para o Índice de Áreas Verdes (IAV) foram encontrados para os setores que compreendem os bairros Vila Itacolomi, Alto da Cruz e São Cristóvão. Analisando os valores de DP, PAV e IAV, nota-se que os setores censitários mais críticos da cidade de Ouro Preto pertencem aos bairros Alto da Cruz, São Cristóvão e Vila Itacolomi, bairros que merecem atenção especial para a utilização e ocupação do seu espaço, sugerindo que os valores obtidos sejam base para orientações e para o disciplinamento da ocupação urbana de suas áreas.

Palavras chaves: áreas verdes, setores censitários, planejamento urbano.

\section{CONTENTS AND PERCENTAGE OF GREEN AREAS FOR THE URBAN PERIMETER OF}

\section{OURO PRETO - MG}

\begin{abstract}
The strong increase of Ouro Preto (MG) city population, together with the lack of effective environmental policies brings several consequences for their in habitants. Trying to reverse this situation or at least minimize these effects, urban environmental specialists have developed several tools and strategies, to help in decisions regarding the planning of urban cities, such as the Percentage of Green Areas (PGA) and the Green Area Index (GAI), among others. This study calculated the Population Density (PD), Percentage of Green Areas (PGA) and Green Area Index (GAI) in the city of Ouro Preto based on IBGE census performed in 2007, obtaining the following results: from $27.9 \mathrm{~km}^{2}$ of urban perimeter, approximately $24 \%\left(6.69 \mathrm{~km}^{2}\right)$ consists of built-up areas, and $76 \%\left(21.09 \mathrm{~km}^{2}\right)$ of green areas. The study has shown that the most populous neighborhoods are Padre Faria, Morro Santana, Morro São João, Nossa Senhora das Dores and Vila Aparecida; the areas with higher Population Density (PD) belong to the neighborhoods Vila Itacolomi, Alto da Cruz and São Cristovão; the lowest Percentages of Green Areas (PGA) were found in São Cristovão, Alto da Cruz and Vila Itacolomi neighborhoods and the worst values of Green Area Index (GAI) were found in the sectors that comprise the neighborhoods of Vila Itacolomi, Alto da Cruz and São Cristovão. Analyzing the results of PD, PGA and GAI note that the most critical areas of Ouro Preto city belong to Alto da Cruz, São Cristovão and Vila Itacolomi neighborhoods that deserve special attention to the use and occupancy of their space, guiding and disciplining the urban occupation.
\end{abstract}

Key words: green areas, census tracts, urban planning.

\footnotetext{
${ }^{1}$. Biólogo especialista em Gestão Ambiental IFMG, mestre em Engenharia Ambiental - UFOP. thiago_lucon@hotmail.com

2 . Ecólogo, Professor Doutor do DEAMB - UFOP, Ouro Preto, MG. jfprado@depro.em.ufop.br

3. Geólogo, Professor Doutor do DEAMB - UFOP, Ouro Preto, MG. sobreira@degeo.ufop.br

${ }^{4}$ recebido em 25.05.2013 e aceito para publicação em 15.09.2013
} 
A cidade de Ouro Preto (MG) é uma das mais conhecidas cidades históricas do Brasil. Imponente por possuir patrimônio histórico e arquitetônico conservado do período colonial do Brasil e conhecida internacionalmente por ser a primeira cidade brasileira tombada como Patrimônio Histórico e Cultural da Humanidade pela United Nations Educational, Scientific and Cultural Organization (UNESCO), desde 1980, possui um conjunto arquitetônico colonial, do século XVIII, bastante conservado e com imponentes e belos exemplares da arquitetura religiosa e civil, construídos no auge do período de exploração aurífera mineira. Além disso, Ouro Preto detém diversas atrações históricas, artísticas e naturais, neste caso, por estar localizada numa área ecótonal dos biomas de Mata Atlântica e Cerrado brasileiros.

Porém, a insistente falta de planejamento, fiscalização e disciplina urbana, principalmente no que diz respeito à ocupação de áreas geologicamente impróprias para assentamentos humanos, vem propiciando o aparecimento de inúmeros problemas geotécnicos relacionados à má utilização do espaço físico, com o aumento de riscos à população com registros inclusive de perdas humanas (SOBREIRA \& FONSECA, 2001).

O crescimento da cidade de Ouro Preto (MG), verificado principalmente a partir dos últimos trinta anos, aliado à falta de políticas públicas urbanas eficazes trouxe inúmeras consequências negativas à comunidade local. A urbanização intensa e principalmente recente torna a cidade cada vez mais inadequada para a ocupação humana, seja pela concentração da população local, pela falta de áreas verdes, aumento da poluição e degradação generalizada e o risco de acidentes naturais ou daqueles provocados pelo homem (LIMA NETO et al, 2007). A antropização dessas áreas, que teve início no período colonial, já proporcionou inúmeros acidentes de deslizamentos no perímetro da cidade podendo destacar os ocorridos em 1979 (PINHEIRO et al, 2003), e os que aconteceram no final de 2011, início de 2012, tendo em ambos eventos registros com vítimas fatais.

A redução das áreas verdes das cidades incide diretamente sobre o bem estar da comunidade local e a antropização desses espaços implica diretamente na redução da diversidade de espécies tanto da flora quanto da fauna o que acaba por causar enormes prejuízos ao ecossistema urbano local.

Segundo Grey \& Deneke (1978), Llardent (1982), Di Fidio (1990), Lombardo (1985), Cavalheiro \& Del Picchia (1992), Guzzo (1999), Milano (1990, 1992, 1994, 1995), Dalcin (2000) \& Andrade (2001), podem-se destacar os seguintes beneficios proporcionados pelas áreas verdes no ambiente urbano:

- Redução da poluição do ar, por meio de processos de oxigenação, na reciclagem de gases a partir de processos fotossintéticos, fixando gases tóxicos, e na retenção física de materiais particulados presentes no ar.

- Interfere positivamente na luminosidade e na temperatura do ar, suaviza as temperaturas extremas, melhora a umidade do ar, conserva a umidade dos solos. 
- Diminui o escoamento superficial das áreas impermeabilizadas, abriga a fauna e influencia no balanço hídrico regional.

- Transmitem bem-estar psicológico; valorizam o visual do espaço urbano; favorece a interação entre as atividades humanas e o meio ambiente e amortecem os ruídos sonoros.

Segundo, MATIAS et al (2008), as áreas verdes urbanas agem simultaneamente nos aspectos físico e psicológico do ser humano, além de contribuir para a formação e o aprimoramento do senso estético, deste modo, são elementos vitais e essências da cidade. É indiscutível, portanto, a importância e o papel positivo que as áreas verdes desempenham nas cidades.

Visando quantificar estas áreas e os seus benefícios, foram desenvolvidos vários indicadores utilizados como ferramentas para o planejamento urbano e ambiental das cidades, tais como: o cálculo da Densidade Populacional (DP), que analisa a relação entre a população e a superfície do território; o Percentual de Áreas Verdes (PAV), que quantifica as áreas não edificadas da cidade; o Índice de Áreas Verdes (IAV), que estabelece a relação entre as áreas verdes remanecentes e a população residente; o Índice de Arborização Urbana (IAUrb), que se preocupa com os espaços arborizados; o Índice de Espaços Livres de Uso Público (IELUP), que contabiliza todas as áreas verdes públicas; o Índice de Cobertura Vegetal em Área Urbana (ICVAU), que representa a proporção de área coberta por vegetação em função da área total de estudo.

Segundo Caporusso \& Matias (2008), os indicadores IAUrb, IELUP, ICVAU são entendidos equivocadamente por alguns pesquisadores como sinônimos do Índice de Áreas Verdes (IAV). Na maioria destes índices, consideram-se apenas os espaços livres de uso público, não podendo, desta forma, ser classificado como índices de áreas verdes de uma cidade ou porção urbana.

Ainda de acordo com Caporusso \& Matias (2008), o índice de áreas verdes (IAV) é um dos indicadores mais utilizados para análise da distribuição espacial da vegetação urbana, sendo frequentemente empregado para comparar as quantidades de áreas verdes entre diferentes cidades, bairros ou setores censitários de uma mesma cidade.

Para Henke-Oliveira (1996), o IAV é fundamental para o planejamento urbano, pois a partir dele permite-se observar a dinâmica populacional e sua relação com as áreas verdes na área urbanizada, possibilitando ao poder público garantir áreas públicas para atendimento das demandas por áreas verdes e equipamentos urbanos diversos.

A metodologia mais usada para o cálculo do IAV considera o produto da divisão entre o somatório das áreas verdes e o número de habitantes locais. Uma forma alternativa e refinada para a estimativa do IAV considera a distribuição espacial das áreas verdes, além de fatores relacionados à distribuição dos benefícios no espaço geográfico limitado, como uma circunferência ou uma poligonal (ZANIN et al., 2007).

No Brasil frequentemente tem-se utilizado o valor de $12 \mathrm{~m}^{2}$ de área verde por habitante como o valor do IAV, frequentemente citado como uma recomendação da Organização das Nações Unidas (ONU). Entretanto, se for seguida essa recomendação, o valor deve ser, segundo Cavalheiro \& Del Picchia (1992), o IAV básico da Alemanha, que é de $13 \mathrm{~m}^{2} /$ habitante. Para a Sociedade Brasileira de Arborização Urbana, o mínimo necessário de áreas verdes públicas 
destinadas à recreação é de $15 \mathrm{~m}^{2} /$ habitante (SBAU, 1996).

Com a finalidade de contribuir para uma discussão sobre o assunto e oferecer dados das áreas verdes de uma cidade tricentenária tombada e com particularidades históricas importantes, o objetivo do presente estudo é contribuir com informações que sirvam de base para um possível “re”planejamento ambiental da cidade de Ouro Preto (MG) por meio do cálculo da Densidade Populacional (DP), do Porcentual de Áreas Verdes (PAV) e do Índice de Áreas Verdes (IAV) para perímetro urbano e dos seus Setores Censitários.

\section{ÁREA DE ESTUDO}

O município de Ouro Preto está localizado na região central do Estado de Minas Gerais, circundado pelos municípios de Catas Altas da
Noruega, Itaverava, Ouro Branco e Congonhas, ao Sul; Belo Vale e Moeda a Oeste; Mariana, a Leste; Itabirito e Santa Bárbara, ao Norte. A área ocupada pelo município é de $1.245,9 \mathrm{~km}^{2}$, tem uma população total de 70.281 habitantes, dos quais 40.214 residem na sede municipal, e uma densidade demográfica municipal de 56,41 $\mathrm{hab} / \mathrm{km}^{2}$ (IBGE, 2010).

A área de estudo onde foram calculados o Percentual de Áreas Verdes (PAV) e o Índice de Áreas Verdes (IAV), compreende todo o perímetro urbano da cidade de Ouro Preto, totalizando 27,71 $\mathrm{Km}^{2}$ distribuídos em 45 setores censitários (IBGE, 2007) e 38 bairros (Figura 1). Observa-se que grande parte do perimetro urbano da cidade de Ouro Preto não está compreendida em bairros, porém está compreendido no interior dos setores censitários locais.

Figura 1: Acima detalhe do limite dos bairros e abaixo o limite dos setores censitários dentro do perímetro urbano da cidade de Ouro Preto.

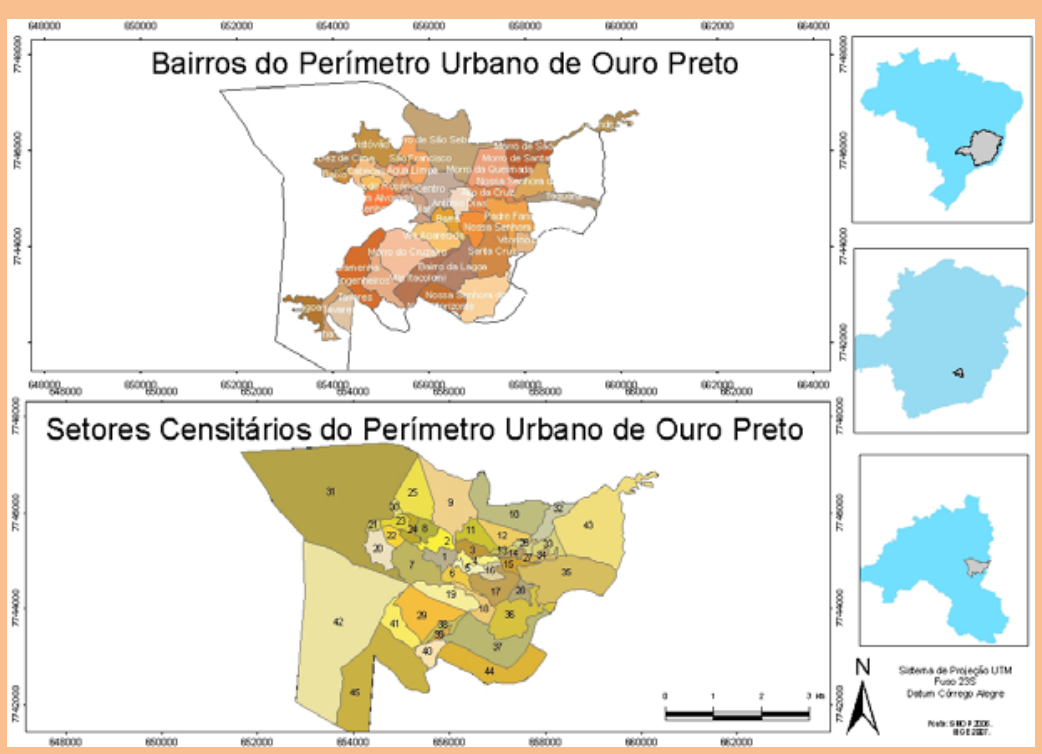


Neste estudo foram utilizados e calculados diferentes indicadores urbanos, alguns dos quais muito difundidos e que são apresentados a seguir, com as respectivas unidades de medidas.

- Densidade Populacional (DP), expresso em habitantes por $\mathrm{m}^{2}$ (hab/ $\mathrm{m}^{2}$ );

- Porcentagem de Áreas Verdes (PAV), expresso em porcentagem (\%);

- Índice de Áreas Verdes (IAV), expresso em $\mathrm{m}^{2}$ de área verde por habitante ( $\left.\mathrm{m}^{2} / \mathrm{hab}\right)$.

Para o cálculo da densidade populacional no perímetro urbano de Ouro Preto foram sobrepostas as seguintes bases cartográficas:

- limite do perímetro urbano de Ouro Preto (SMPOP) e

- levantamento da população por setor censitário de 2007 (IBGE).

Para os cálculos foram utilizados os dados do Censo de 2007, por este se apresentar dispostos por setores censitários. Os novos dados gerados com o censo do IBGE de 2010 não foram usados no presente estudo por ainda estarem em processamento por aquele Instituto.

Os setores censitários são demarcados pelo IBGE, obedecendo a critérios de operacionalização da coleta de dados, de tal maneira que abranjam uma área que possa ser percorrida por um único recenseador em um mês e que possua em torno de 250 a 350 domicílios (em áreas urbanas). Para realizar o censo demográfico de 2007 o IBGE dividiu o território nacional 159.821 setores censitários dos quais 18.799 pertencem ao Estado de Minas Gerais.

Para fins estatísticos, os limites dos setores censitários devem respeitar os limites territoriais legalmente definidos e estabelecidos, como o perímetro urbano da cidade, porém não possuem relação alguma com os limites dos bairros das cidades. Os mesmos devem apenas estar contidos no perímetro urbano, o que dificulta a obtenção de dados estatísticos mais fidedignos, como por exemplo, a densidade populacional de cada bairro de uma cidade.

Para obtenção dos valores de Percentual de Áreas Verdes (PAV) foram sobrepostas as seguintes bases cartográficas:

- Mapa das áreas verdes localizadas no perímetro urbano (LUCON, 2011).

- Mapa da delimitação do perímetro urbano e dos bairros de Ouro Preto (Secretaria Municipal de Patrimônio de Ouro Preto - SMPOP).

Após a sobreposição dessas bases, foi possível obter os valores do Percentual de Áreas Verdes (PAV) para o perímetro urbano, no conjunto e para cada setor censitário. O porcentual de PAV é obtido por meio de regra de três simples, onde:

Área estudada (AE) $100 \%$

Áreas verdes (AV) $\mathrm{X} \%$

A metodologia mais utilizada para o cálculo do Índice de áreas Verdes (IAV) considera o produto da divisão entre o somatório das áreas verdes e o número de habitantes, resultando um cálculo simplificado, sendo esse índice sempre dependente de fatores demográficos.

Para obtenção dos valores do IAV, foi necessária a sobreposição das seguintes bases cartográficas:

- Mapa das áreas verdes localizadas no perímetro urbano (LUCON, 2011).

- Mapa com a delimitação do perímetro urbano e bairros de Ouro Preto 
(Secretaria Municipal de Patrimônio de Ouro Preto - SMPOP).

- Mapa com a distribuição demográfica (densidade populacional) disposta em setores censitários (IBGE, 2007).

Após a sobreposição dessas bases, foi possível obter os valores de IAV para o perímetro urbano e para os diferentes setores censitários de Ouro Preto.
Neste estudo, não foi possível obter o IAV de cada bairro da cidade de Ouro Preto, devido à incongruência das bases cartográficas contendo a delimitação dos bairros e a delimitação dos setores censitários. De acordo com o IBGE (2007), a cidade apresenta 45 setores censitários, mas, segundo a Secretaria Municipal de Patrimônio de Ouro Preto (SMPOP) são 38 bairros no perímetro urbano.

\section{RESULTADOS}

Para se conhecer os indicadores foi necessário identificar, a localização e tamanho das áreas verdes inseridas no perímetro urbano de Ouro Preto, a delimitação do perímetro urbano e bairros da cidade e a distribuição demográfica de cada um dos setores censitários, segundo o IBGE (2007).

\section{População e densidade populacional dos setores censitários de Ouro Preto}

De acordo com a sobreposição das bases cartográficas descritas, o perímetro urbano de Ouro Preto tem uma população total de 37.918 habitantes (IBGE, 2007) distribuídos em 45 setores censitários.

Com dados da Pró-Reitoria de Graduação (PROGRAD) e obtidos na Chefia do Setor de Diplomas e Certificados da Pró-Reitoria de Pesquisa e Pós-Graduação (PROPP) da Universidade Federal de Ouro Preto (UFOP), o número de estudantes matriculados em 2011 nos cursos de graduação oferecidos no Campus Morro do Cruzeiro e no Campus Centro
Histórico é 5.962, enquanto são 646 os estudantes de pós-graduação. Soma-se a esses números a população de alunos matriculados no Instituto Federal de Minas Gerais (IFMG), com um total de 1.361 alunos, dos quais 577 são oriundos de outras cidades.

Dessa forma, partindo da hipótese de que os alunos da UFOP e IFMG são em sua maioria oriundos de outras cidades, 7.187 estudantes são considerados pelo IBGE como população flutuante de Ouro Preto, portanto não contabilizados no censo demográfico da cidade. Tal fato pode gerar falsas interpretações quanto à densidade demográfica da cidade e dos seus respectivos setores censitários.

A Figura 2, a título de exemplo, apresenta a localização dos dois setores censitários (IGBE, 2007) mais populosos da cidade, como pode-se observar na Tabela 1, sobrepostos ao mapa do perímetro urbano com a delimitação geográfica dos bairros da cidade. O setor censitário $\mathrm{n}^{\circ} 17$ apresenta 683 habitantes enquanto o setor $\mathrm{n}^{\circ} 19$, 750 habitantes, ambos situados na região central do perímetro urbano de Ouro Preto. 
Figura 2: Mapa do perímetro urbano de Ouro Preto apresentando a localização dos dois setores censitários mais populosos da cidade (IBGE, 2007).

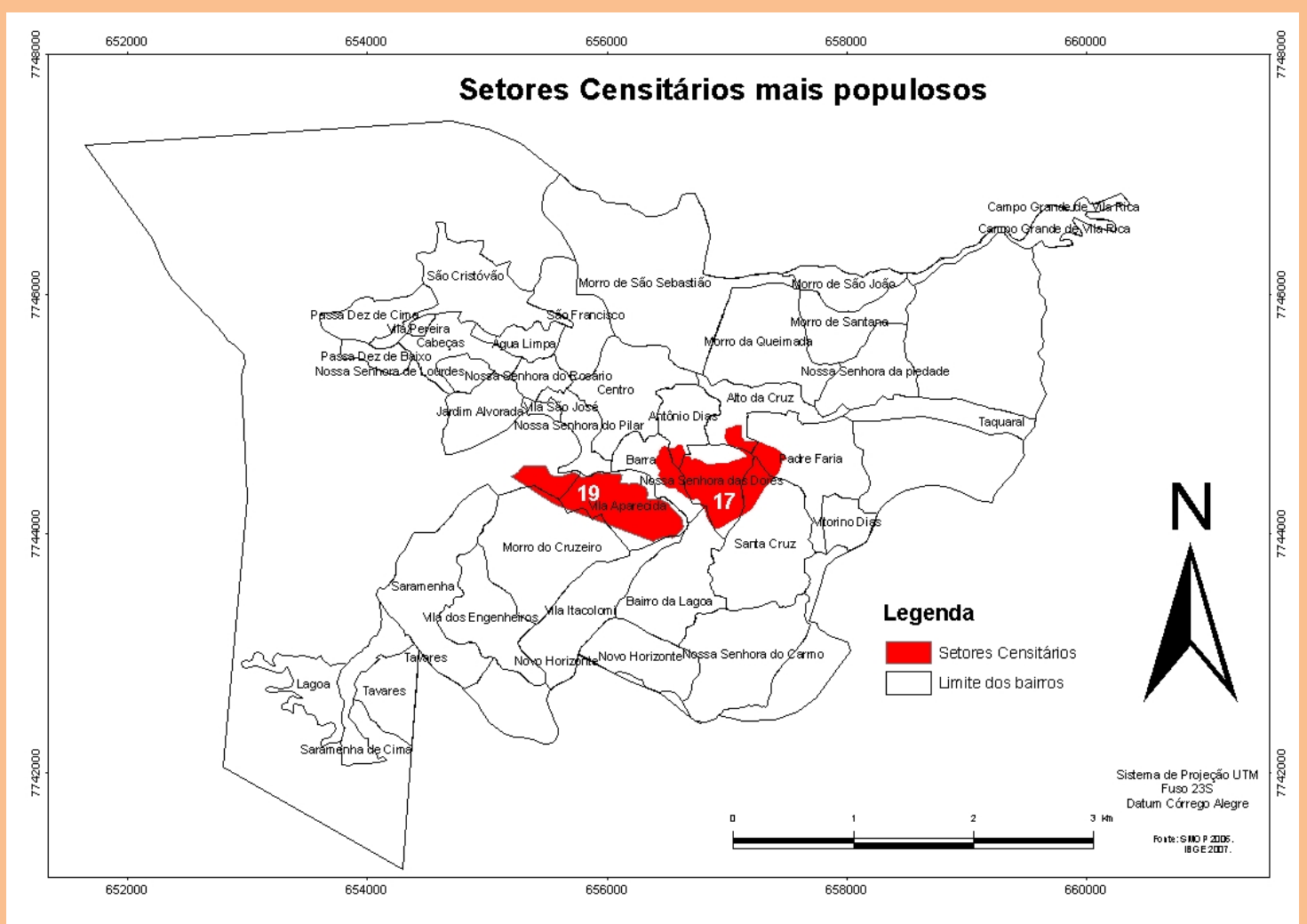

Tabela 1: População por setor Censitário da cidade de Ouro Preto.

Table 1: Population by Census sector of the city of Ouro Preto.

\begin{tabular}{c|c|c|c|c|c}
\hline $\begin{array}{c}\text { Setor } \\
\text { Censitário }\end{array}$ & $\begin{array}{c}\text { População } \\
\text { (hab.) }\end{array}$ & $\begin{array}{c}\text { Setor } \\
\text { Censitário }\end{array}$ & $\begin{array}{c}\text { População } \\
\text { (hab.) }\end{array}$ & $\begin{array}{c}\text { Setor } \\
\text { Censitário }\end{array}$ & $\begin{array}{c}\text { População } \\
\text { (hab.) }\end{array}$ \\
\hline $\mathbf{1}$ & 397 & $\mathbf{1 6}$ & 951 & $\mathbf{3 1}$ & 1088 \\
\hline $\mathbf{2}$ & 743 & $\mathbf{1 7}$ & 1371 & $\mathbf{3 2}$ & 1330 \\
\hline $\mathbf{3}$ & 871 & $\mathbf{1 8}$ & 683 & $\mathbf{3 3}$ & 1090 \\
\hline $\mathbf{4}$ & 754 & $\mathbf{1 9}$ & 1442 & $\mathbf{3 4}$ & 597 \\
\hline $\mathbf{5}$ & 687 & $\mathbf{2 0}$ & 999 & $\mathbf{3 5}$ & 593 \\
\hline $\mathbf{6}$ & 589 & $\mathbf{2 1}$ & 67 & $\mathbf{3 6}$ & 999 \\
\hline $\mathbf{7}$ & 1114 & $\mathbf{2 2}$ & 682 & $\mathbf{3 7}$ & 1108 \\
\hline $\mathbf{8}$ & 750 & $\mathbf{2 3}$ & 633 & $\mathbf{3 8}$ & 1099 \\
\hline $\mathbf{9}$ & 745 & $\mathbf{2 4}$ & 683 & $\mathbf{3 9}$ & 606 \\
\hline $\mathbf{1 0}$ & 454 & $\mathbf{2 5}$ & 966 & $\mathbf{4 0}$ & 990 \\
\hline $\mathbf{1 1}$ & 549 & $\mathbf{2 6}$ & 662 & $\mathbf{4 1}$ & 587 \\
\hline $\mathbf{1 2}$ & 854 & $\mathbf{2 7}$ & 753 & $\mathbf{4 2}$ & 879 \\
\hline $\mathbf{1 3}$ & 495 & $\mathbf{2 8}$ & 1239 & $\mathbf{4 3}$ & 845 \\
\hline $\mathbf{1 4}$ & 782 & $\mathbf{2 9}$ & 916 & $\mathbf{4 4}$ & 958 \\
\hline $\mathbf{1 5}$ & 1324 & $\mathbf{3 0}$ & 850 & $\mathbf{4 5}$ & 1124 \\
\hline
\end{tabular}

O setor censitário nº 19 do IBGE é formado por algumas áreas inseridas no perímetro urbano de Ouro Preto, porém parte dele não está compreendida dentro de nenhum bairro, enquanto grande parte se insere no Bairro Vila Aparecida. Insere-se ainda nesse setor pequenas porções do Bairro Morro do Cruzeiro, que surgiu após a criação da UFOP em 1969, e que

ÍNDICE E PERCENTUAL DE ÁREAS VERDES PARA... 
atualmente vem sofrendo grande adensamento populacional. Em termos de distribuição espacial, infra-estrutura e topografia constata-se grande disparidade física e social entre os bairros inseridos no setor censitário $\mathrm{n}^{\circ} 19$. O setor censitário $\mathrm{n}^{\circ} 17$ é formado por grande parte do bairro Nossa Senhora das Dores e partes dos bairros Santa Cruz, Padre Faria, Alto da Cruz, Antonio Dias e Barra.
Os valores relativos às maiores e menores densidades populacionais são apresentados na Figura 3 e Tabela 2. Os setores censitários que apresentam maior densidade populacional, 9457 $\mathrm{hab} / \mathrm{m}^{2}$ e $15060 \mathrm{hab} / \mathrm{m}^{2}$ foram respectivamente os setores $n^{\circ} 27$ e $n^{\circ} 30$. O setor censitário $n^{\circ} 27$ está compreendido no Bairro Alto da Cruz e setor censitário nº 30 no Bairro São Cristóvão.

Figura 3: Mapa do perímetro urbano de Ouro Preto com as maiores e menores densidades populacionais.

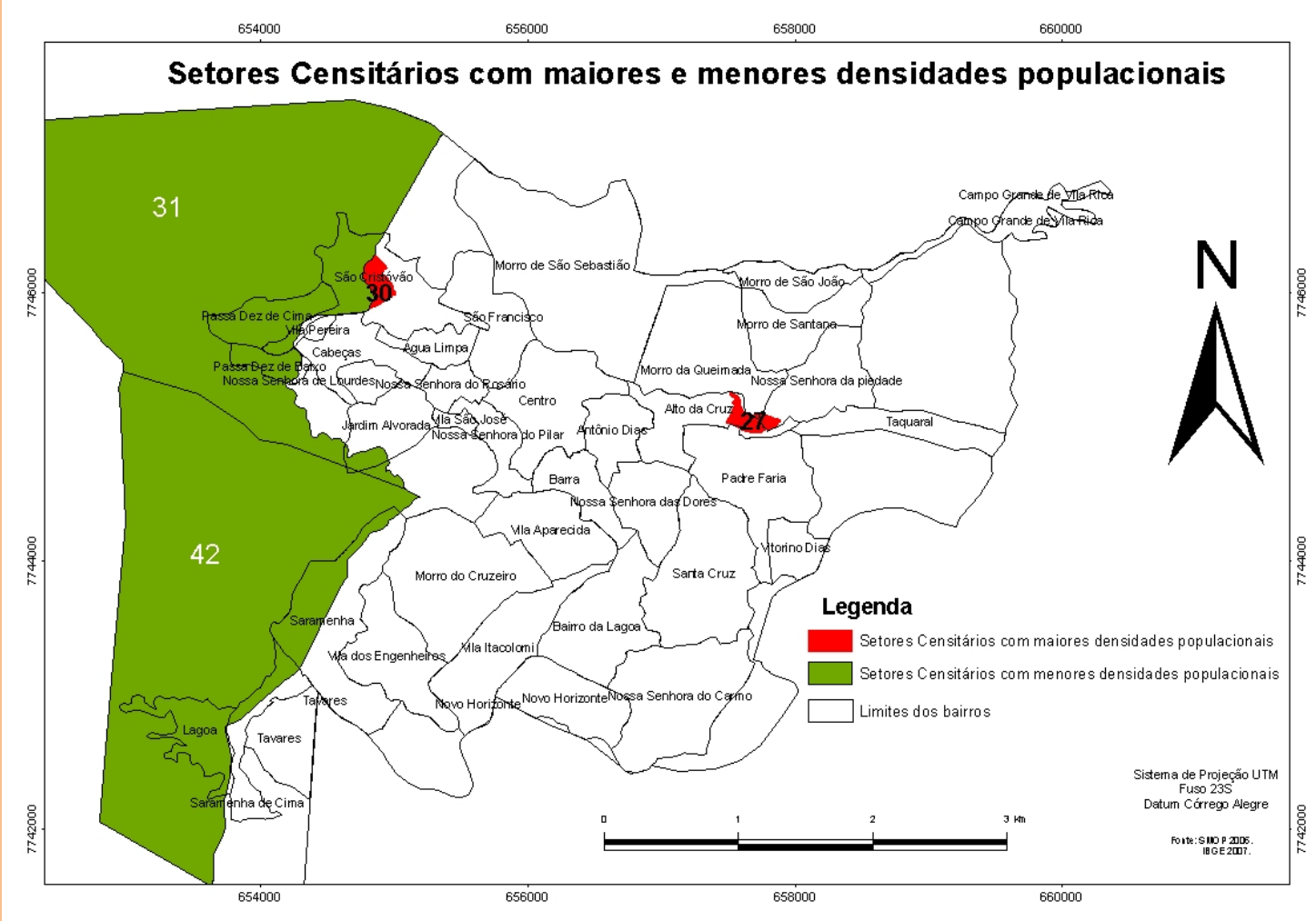

Os setores censitários com menores densidades populacionais são os de $n^{\circ} 42$ e 31 . O primeiro compreende o Bairro Lagoa e porções do Saramenha e o segundo os Bairros Passa Dez de Cima, Passa Dez de Baixo e São Cristóvão.

\section{Porcentagem de áreas verdes (PAV)}

Para o cálculo do PAV, são consideradas todas as áreas verdes da cidade, sejam elas compostas por vegetação herbácea, arbustiva, arbórea ou as áreas reflorestadas com eucaliptos, enquanto as demais tipologias: áreas construídas, arruamentos e solo exposto, foram enquadradas como áreas urbanizadas.

O perímetro urbano de Ouro Preto apresenta 75,84\% de áreas verdes e 24,16\% de áreas urbanizadas, correspondendo respectivamente a $21,16 \mathrm{~km}^{2}$ e $6,74 \mathrm{~km}^{2}$. Destaca-se que os dados populacionais são de 2007, enquanto o mapa de áreas verdes do perímetro urbano é de 2010.

Os valores do PAV dos 45 setores censitários variam de $7,13 \%$ a $94,41 \%$ conforme é possivel observar na 
Tabela 3. Na Figura 4, observa-se o melhor e pior valor para PAV.

Tabela 2: Densidades populacionais por setor censitário da cidade de Ouro Preto.

\begin{tabular}{c|c|c|c|c|c}
\hline $\begin{array}{c}\text { Setor } \\
\text { Censitário }\end{array}$ & $\begin{array}{c}\text { Densidade } \\
\text { pop. }\end{array}$ & $\begin{array}{c}\text { Setor } \\
\text { Censitário }\end{array}$ & $\begin{array}{c}\text { Densidade } \\
\text { pop. }\end{array}$ & $\begin{array}{c}\text { Setor } \\
\text { Censitário }\end{array}$ & $\begin{array}{c}\text { Densidade } \\
\text { pop. }\end{array}$ \\
\hline $\mathbf{1}$ & 1804 & $\mathbf{1 6}$ & 7925 & $\mathbf{3 1}$ & 197 \\
\hline $\mathbf{2}$ & 3377 & $\mathbf{1 7}$ & 3115 & $\mathbf{3 2}$ & 4925 \\
\hline $\mathbf{3}$ & 4838 & $\mathbf{1 8}$ & 2845 & $\mathbf{3 3}$ & 5736 \\
\hline $\mathbf{4}$ & 5026 & $\mathbf{1 9}$ & 3353 & $\mathbf{3 4}$ & 8528 \\
\hline $\mathbf{5}$ & 6870 & $\mathbf{2 0}$ & 3027 & $\mathbf{3 5}$ & 452 \\
\hline $\mathbf{6}$ & 3272 & $\mathbf{2 1}$ & 1155 & $\mathbf{3 6}$ & 1407 \\
\hline $\mathbf{7}$ & 1826 & $\mathbf{2 2}$ & 5246 & $\mathbf{3 7}$ & 1045 \\
\hline $\mathbf{8}$ & 5000 & $\mathbf{2 3}$ & 4521 & $\mathbf{3 8}$ & 9158 \\
\hline $\mathbf{9}$ & 723 & $\mathbf{2 4}$ & 4878 & $\mathbf{3 9}$ & 10100 \\
\hline $\mathbf{1 0}$ & 498 & $\mathbf{2 5}$ & 1590 & $\mathbf{4 0}$ & 4714 \\
\hline $\mathbf{1 1}$ & 1893 & $\mathbf{2 6}$ & 8275 & $\mathbf{4 1}$ & 1544 \\
\hline $\mathbf{1 2}$ & 2754 & $\mathbf{2 7}$ & 15060 & $\mathbf{4 2}$ & 191 \\
\hline $\mathbf{1 3}$ & 9900 & $\mathbf{2 8}$ & 8850 & $\mathbf{4 3}$ & 447 \\
\hline $\mathbf{1 4}$ & 11500 & $\mathbf{2 9}$ & 1145 & $\mathbf{4 4}$ & 1008 \\
\hline $\mathbf{1 5}$ & 9457 & $\mathbf{3 0}$ & 17000 & $\mathbf{4 5}$ & 579 \\
\hline
\end{tabular}

Figura 4: Mapa apresentando a distribuição do melhor e pior valor de Porcentagens de Áreas Verdes (PAV).

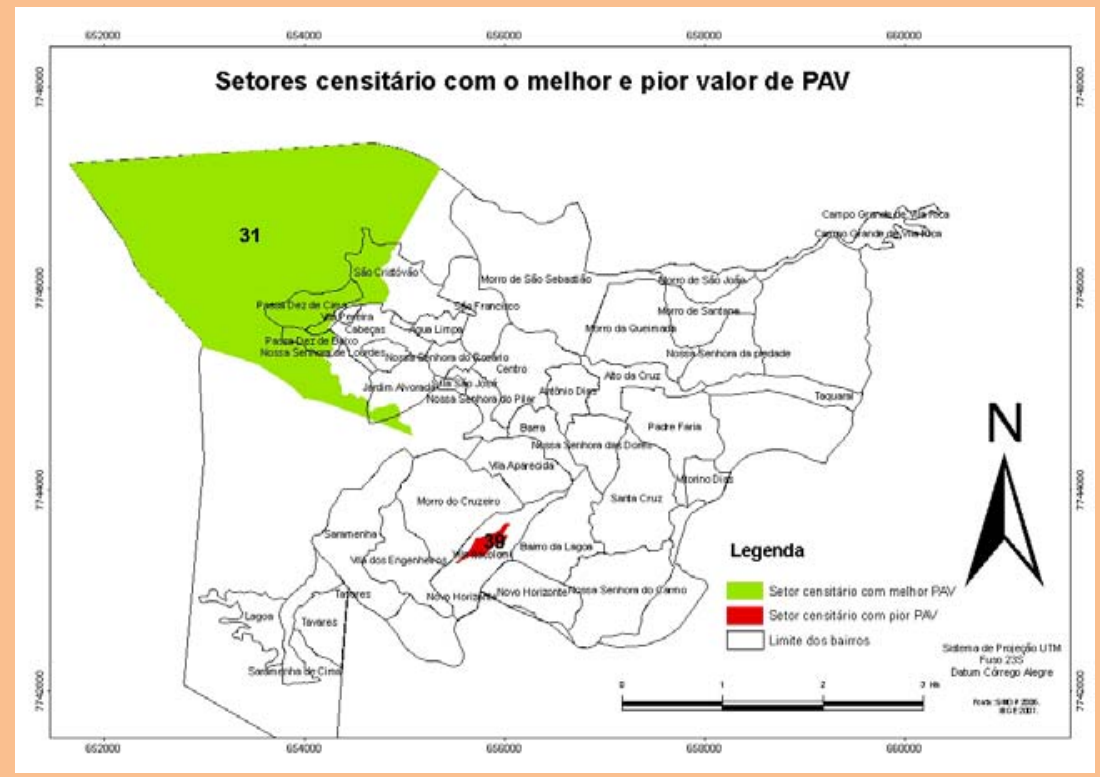

O pior resultado encontrado para o PAV foi para o setor censitário $\mathrm{n}^{0} 39$, inserido em parte do Bairro Vila Itacolomi, com 7,13\% de áreas verdes, enquanto o melhor resultado foi para o setor censitário $n^{0} 31$, que compreende grande parte de áreas não pertencentes a nenhum bairro (localizado a noroeste do perimetro urbano de Ouro Preto) e pelo Bairro Passa Dez de Cima e parte dos Bairros São Cristóvão e Passa Dez de Baixo, com 94\% de áreas verdes. 
Tabela 3: Percentual de áreas verdes por setor censitário da cidade de Ouro Preto.

\begin{tabular}{c|c|c|c|c|c}
\hline $\begin{array}{c}\text { Setor } \\
\text { Censitário }\end{array}$ & $\begin{array}{c}\text { PAV } \\
(\%)\end{array}$ & $\begin{array}{c}\text { Setor } \\
\text { Censitário }\end{array}$ & PAV (\%) & $\begin{array}{c}\text { Setor } \\
\text { Censitário }\end{array}$ & PAV (\%) \\
\hline $\mathbf{1}$ & 24,33 & $\mathbf{1 6}$ & 33,41 & $\mathbf{3 1}$ & 94,41 \\
\hline $\mathbf{2}$ & 52,56 & $\mathbf{1 7}$ & 77,27 & $\mathbf{3 2}$ & 42,23 \\
\hline $\mathbf{3}$ & 46,74 & $\mathbf{1 8}$ & 61,67 & $\mathbf{3 3}$ & 47,23 \\
\hline $\mathbf{4}$ & 30,28 & $\mathbf{1 9}$ & 55,97 & $\mathbf{3 4}$ & 21,13 \\
\hline $\mathbf{5}$ & 29,56 & $\mathbf{2 0}$ & 76,17 & $\mathbf{3 5}$ & 76,31 \\
\hline $\mathbf{6}$ & 51,81 & $\mathbf{2 1}$ & 40,45 & $\mathbf{3 6}$ & 68,93 \\
\hline $\mathbf{7}$ & 79,4 & $\mathbf{2 2}$ & 48,84 & $\mathbf{3 7}$ & 59,09 \\
\hline $\mathbf{8}$ & 44,74 & $\mathbf{2 3}$ & 35,24 & $\mathbf{3 8}$ & 11,29 \\
\hline $\mathbf{9}$ & 83,46 & $\mathbf{2 4}$ & 40,99 & $\mathbf{3 9}$ & 7,13 \\
\hline $\mathbf{1 0}$ & 85,37 & $\mathbf{2 5}$ & 81,44 & $\mathbf{4 0}$ & 39,79 \\
\hline $\mathbf{1 1}$ & 78,36 & $\mathbf{2 6}$ & 45,94 & $\mathbf{4 1}$ & 64,3 \\
\hline $\mathbf{1 2}$ & 74,18 & $\mathbf{2 7}$ & 24,57 & $\mathbf{4 2}$ & 84,56 \\
\hline $\mathbf{1 3}$ & 33,43 & $\mathbf{2 8}$ & 38,92 & $\mathbf{4 3}$ & 88,83 \\
\hline $\mathbf{1 4}$ & 13,92 & $\mathbf{2 9}$ & 48,21 & $\mathbf{4 4}$ & 73,82 \\
\hline $\mathbf{1 5}$ & 22,41 & $\mathbf{3 0}$ & 14,15 & $\mathbf{4 5}$ & 80,5 \\
\hline
\end{tabular}

\section{Índices de áreas verdes (IAV)}

Para o cálculo do índice de áreas verdes (IAV) utilizou-se a seguinte operação:

$$
I A V=\frac{\text { Áreas verdes }\left(\mathrm{m}^{2}\right)}{\text { Habitantes }}
$$

Onde: Áreas verdes = Vegetação herbácea, arbustiva, arbórea e revegetação com eucalitptos.

Na tentativa de obter valores de IAV que melhor representem a realidade de Ouro Preto, foram simuladas três situações. Na primeira, foram contabilizadas todas as áreas verdes do perímetro urbano e a população urbana disponibilizada pelo IBGE (2007).

$\therefore I A V=\underline{\text { Áreas verdes }}=\underline{21.161 .215}=556,697$ $\mathrm{m}^{2}$ de área verde/ habitante.

Habitantes $\quad 37.918$

Na segunda situação, foram contabilizadas todas as áreas verdes do perímetro urbano, somandose a população flutuante com cerca de 7.185 habitantes à população disponibilizada pelo IBGE (2007) de 37.918 habitantes.

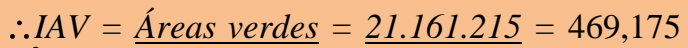
$\mathrm{m}^{2}$ de área verde/ habitante.

Habitantes 45.103
$\mathrm{Na}$ terceira situação de IAV, foram contabilizadas as áreas verdes inseridas nas áreas ocupadas pelos bairros com a população flutuante (estudantes) somada à população disponibilizada pelo IBGE (2007).

$\therefore I A V=\underline{\text { Áreas verdes }}=\underline{8.679 .545}=192,438$ $\mathrm{m}^{2}$ de área verde/ habitante.

$$
\text { Habitantes } 45.103
$$

Observa-se que a primeira situação apresenta o maior valor de IAV, por ter-se incluído áreas que estão dentro do perimetro urbano da cidade de Ouro Preto e dos seus setores censitários, porém não compreendidas no interior de bairros da cidade em sua formulação. Em contrapartida, a terceira situação apresentou o menor valor de IAV, por ter-se excluído as áreas não compreendidas dentro dos bairros da cidade e também incluído a população flutuante no cálculo.

A Figura 5 apresenta a localização dos melhores e piores valores de IAV. Pode-se observar de acordo com a Tabela 4, que quatro setores censitários (38, 14, 30 e 39) compreendendo 
parte dos bairros São Cristovão, Vila Itacolomi e Alto da Cruz, onde o IAV está abaixo dos valores recomendados pela Sociedade Brasileira de Arborização Urbana (SBAU), que é de $15 \mathrm{~m}^{2}$ de área verde/habitante. Dentre esses, dois setores censitários (30 e 39) estão abaixo do recomendado pela ONU, que é de $12 \mathrm{~m}^{2}$ de área verde/habitante.

Figura 5: Mapa apresentando a distribuição dos melhores e piores valores dos Índices de Áreas Verdes (IAV).

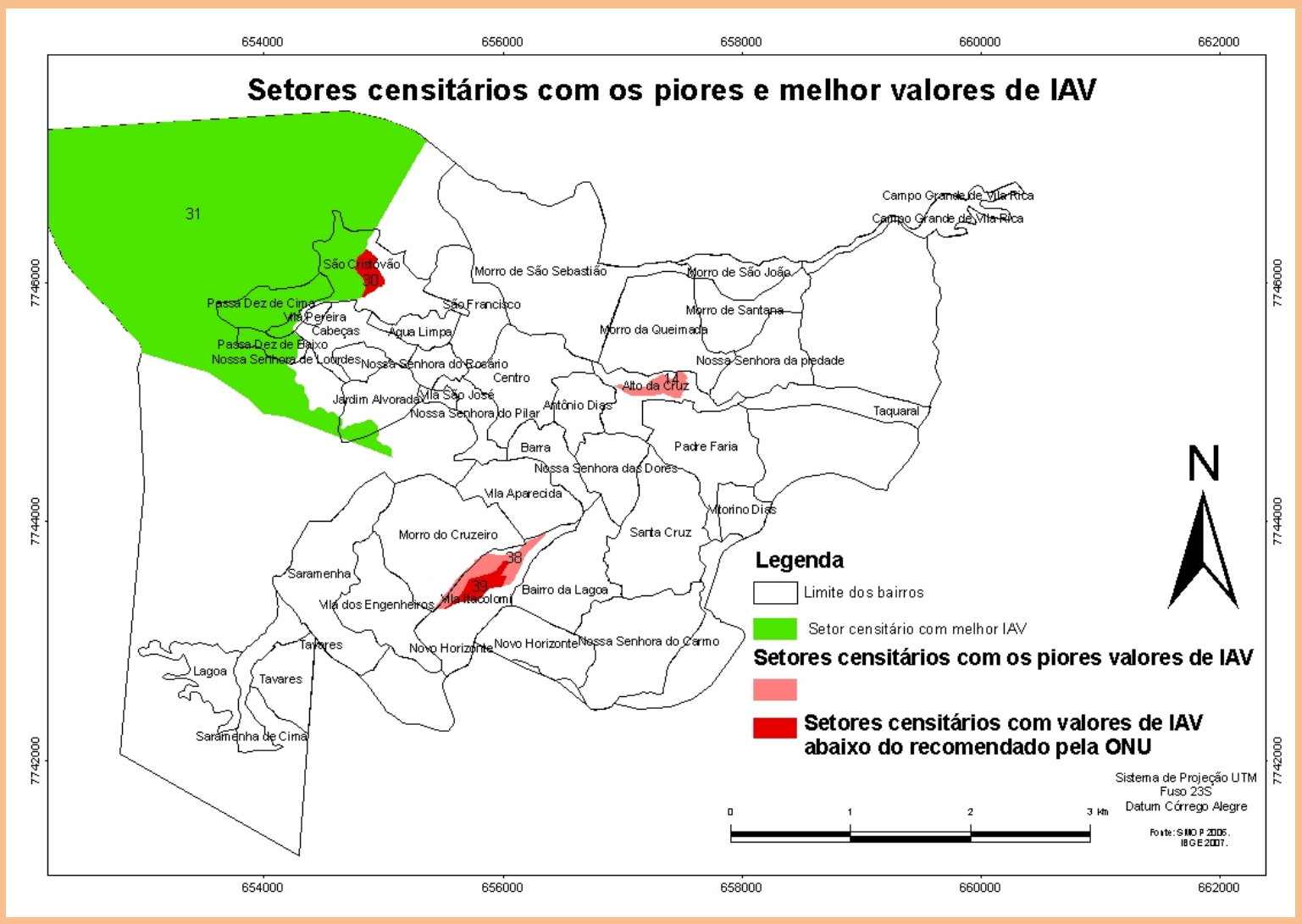

O pior resultado de IAV foi obtido para o setor censitário $\mathrm{n}^{\circ} 39$, inserido em parte do Bairro Vila Itacolomi, com $7,5 \mathrm{~m}^{2}$ de área verde por habitante, enquanto o melhor resultado foi para o setor censitário $n^{\circ} 31$, que compreende o Bairro Passa Dez de Cima e partes dos Bairros São Cristóvão e Passa Dez de Baixo, com 4.797 $\mathrm{m}^{2}$ de área verde por habitante. Vale destacar que grande parte deste setor censitário está fora das áreas dos bairros, conforme a Secretaria Municipal de Patrimônio de Ouro Preto, o que por sua vez apresenta uma baixa população repercutindo diretamente no alto valor para o Índice de áreas verdes (IAV). 
Tabela 4: Índices de áreas verdes por setor censitário da cidade de Ouro Preto.

\begin{tabular}{c|c|c|c|c|c}
\hline $\begin{array}{c}\text { Setor } \\
\text { Censitário }\end{array}$ & $\begin{array}{c}\text { IAV }\left(\mathrm{m}^{2} \text { de área }\right. \\
\text { verde/hab.) }\end{array}$ & $\begin{array}{c}\text { Setor } \\
\text { Censitário }\end{array}$ & $\begin{array}{c}\text { IAV }\left(\mathrm{m}^{2} \text { de área }\right. \\
\text { verde/hab.) }\end{array}$ & $\begin{array}{c}\text { Setor } \\
\text { Censitário }\end{array}$ & $\begin{array}{c}\text { IAV }\left(\mathrm{m}^{2} \text { de área }\right. \\
\text { verde/hab.) }\end{array}$ \\
\hline $\mathbf{1}$ & 135,46 & $\mathbf{1 6}$ & 44,05 & $\mathbf{3 1}$ & 4797,08 \\
\hline $\mathbf{2}$ & 157,2 & $\mathbf{1 7}$ & 253,04 & $\mathbf{3 2}$ & 88,47 \\
\hline $\mathbf{3}$ & 99,7 & $\mathbf{1 8}$ & 220,32 & $\mathbf{3 3}$ & 83,75 \\
\hline $\mathbf{4}$ & 60,9 & $\mathbf{1 9}$ & 168,71 & $\mathbf{3 4}$ & 25,67 \\
\hline $\mathbf{5}$ & 46,03 & $\mathbf{2 0}$ & 255,67 & $\mathbf{3 5}$ & 1688,78 \\
\hline $\mathbf{6}$ & 164,93 & $\mathbf{2 1}$ & 353,48 & $\mathbf{3 6}$ & 496,72 \\
\hline $\mathbf{7}$ & 419,2 & $\mathbf{2 2}$ & 97,25 & $\mathbf{3 7}$ & 569,18 \\
\hline $\mathbf{8}$ & 94,74 & $\mathbf{2 3}$ & 78,5 & $\mathbf{3 8}$ & 12,44 \\
\hline $\mathbf{9}$ & 1124,6 & $\mathbf{2 4}$ & 86,48 & $\mathbf{3 9}$ & 7,5 \\
\hline $\mathbf{1 0}$ & 1726,29 & $\mathbf{2 5}$ & 517,52 & $\mathbf{4 0}$ & 87,4 \\
\hline $\mathbf{1 1}$ & 428,12 & $\mathbf{2 6}$ & 57,19 & $\mathbf{4 1}$ & 421,12 \\
\hline $\mathbf{1 2}$ & 275,46 & $\mathbf{2 7}$ & 17,77 & $\mathbf{4 2}$ & 4425,68 \\
\hline $\mathbf{1 3}$ & 34,05 & $\mathbf{2 8}$ & 46,56 & $\mathbf{4 3}$ & 1997,1 \\
\hline $\mathbf{1 4}$ & 12,24 & $\mathbf{2 9}$ & 426,13 & $\mathbf{4 4}$ & 738,61 \\
\hline $\mathbf{1 5}$ & 23,88 & $\mathbf{3 0}$ & 9,19 & $\mathbf{4 5}$ & 1391,83 \\
\hline
\end{tabular}

\section{DISCUSSÃO}

Para fins estatísticos do IBGE, os limites dos setores censitários devem respeitar os limites territoriais legalmente definidos e estabelecidos como o perímetro urbano da cidade, porém os mesmos não têm nenhuma relação com os limites dos bairros, devendo os mesmos estarem contidos no perímetro urbano, o que dificulta a obtenção de dados estatísticos como a densidade populacional e índices de áreas verdes por bairro da cidade. Não há no município um censo populacional local por bairros da cidade.

\section{População e densidade populacional dos setores censitários de Ouro Preto}

Os bairros mais populosos, conforme dados do presente estudo, já foram apontados por Castro (2006) como os mais críticos no quesito antropização de áreas de risco e deslizamento de encostas, com registro de inúmeros acidentes geotécnicos, como é o caso do Bairro Vila Aparecida e dos bairros que se localizam na Serra de Ouro Preto, Padre Faria e Santa Cruz.
Os principais acidentes oriundos por deslizamentos de massa desses locais se agravaram devido à ocupação irregular de áreas de risco, como as APPs com declividades superiores a $45^{\circ}$, além de atuais práticas inadequadas de construção, ocupação de antigas áreas de mineração e de depósitos de rejeitos daquelas atividades do passado, disposição inadequada de resíduos da construção civil e entulhos, falta de saneamento básico (afastamento de esgoto), precários sistemas de drenagens, baixa qualidade das construções residenciais, dentre outros problemas.

Observa-se que os bairros de maiores densidades populacionais, o São Cristóvão e o Alto da Cruz, foram apontados por Castro (2006) como os que apresentam inúmeros acidentes com movimentos de massa, o que ocorre em consequência da má utilização do espaço físico devido sua alta densidade populacional.

As informações relacionadas tanto à população quanto à densidade populacional por setor Thiago Nogueira Lucon et al. 
censitário são de suma importância para gestão do município. Isso porque esses dados indicam a necessidade de maior demanda por fiscalização e planejamento, tanto para suprir as necessidades da população local, quanto para garantir a conservação e recuperação das APPs remanescentes, além de evitar problemas relacionados à ocupação irregular de possíveis áreas de risco, entre outros motivos.

\section{Porcentagem de áreas verdes (PAV)}

Para Cavalheiro et al. (1999 apud Buccheri Filho \& Nucci, 2006), a vegetação e o solo urbano (permeável) devem ocupar, no mínimo, $70 \%$ da área, oferecendo diversos usos e serviços ambientais à população. No entanto pode-se observar que 31 dos 45 setores censitários do perímetro urbano de Ouro Preto apresentam PAV inferior a 70\% e 8 apresentam PAV inferior a $25 \%$, portanto considerados bem críticos, demonstrando a pressão de retirada que essas áreas vêm sofrendo ao longo dos anos, o que repercute diretamente na supressão das APP urbanas.

\section{Índices de áreas verdes (IAV)}

De acordo com Caporusso \& Matias (2008), a falta de consenso em relação ao termo áreas verdes urbanas reflete, entre outras consequências, na dificuldade para o mapeamento e classificação/categorização dessas áreas, além das infrutíferas tentativas de comparação entre os diferentes IAV obtidos com o emprego de diferentes metodologias para diferentes cidades.

A necessidade do conhecimento dessas áreas no ambiente urbano destaca-se principalmente devido às funções que elas desempenham na melhoria das condições ambientais e de vida da população, na diversificação da paisagem construída, nos aspectos psicológicos e paisagísticos, dentre outras consequências.

Os resultados de IAV da cidade de Ouro Preto mostraram-se muito elevado em relação aos de outras cidades como Curitiba (PR), com 9,55 m² de área verde/hab. (considerada cidade ecológica do Brasil), Bauru (SP), com 6,29 $\mathrm{m}^{2}$ de área verde/hab. (OLIVEIRA et al. 1999 apud JESUS \& BRAGA, 2005); Goiânia (GO), com 100,25 $\mathrm{m}^{2}$ de área verde/hab. (MARTINS JUNIOR, 2002 apud HARDER et al., 2006); São Carlos (SP), com 2,65 $\mathrm{m}^{2}$ de área verde/hab. (HENKE-OLIVEIRA, 1996); Vinhedo (SP), com 2,19 $\mathrm{m}^{2}$ de área verde/hab (HARDER et al., 2006); Lavras (MG), com 0,34 $\mathrm{m}^{2}$ de área verde/hab.(CARVALHO, 2001) e Piracicaba (SP), com $2,2 \mathrm{~m}^{2}$ de área verde por hab. (LIMA, 1993).

A grande diferença entre os valores de IAV para as diferentes cidades decorre principalmente dos critérios para categorização das chamadas áreas verdes urbanas e das metodologias utilizadas para o seu cálculo.

Em certos trabalhos, as áreas verdes são mapeadas sem critérios de classificação ou categorização, apresentando somente áreas públicas e/ou privadas, mas em outros se percebe a preocupação com a classificação mais adequada à área estudada, com as diferenças de definição de áreas verdes, entre outras.

Em trabalho anterior, Jesus \& Braga (2005) obteveram para a área urbana de Estância de Águas de São Pedro (SP), o IAV de 936,095 $\mathrm{m}^{2}$ /habitante, em que os altos valores observados se devem ao diminuto tamanho populacional local e à pequena extensão da cidade.

Em Ouro Preto, o IAV é considerado elevado em determinadas localidades (setores censitários), não só pela quantidade de áreas

ÍNDICE E PERCENTUAL DE ÁREAS VERDES PARA... 
verdes ainda disponível, mas pela reduzida população nos setores censitários trabalhados e também por particularidades locais consideradas de difícil ocupação seja pela topografia extremamente acidentada, infra estrutura urbana precária e instabilidade geral dos terrenos, devido à suas constituições geológicas e particularidades geotécnicas.

O setor censitário $n^{\circ} 30$ que é formado por uma boa porção do Bairro São Cristóvão, apresenta a maior densidade populacional da cidade de Ouro Preto, com $17.000 \mathrm{hab} / \mathrm{km}^{2}$, índice que influencia diretamente na disponibilidade de áreas verdes, $(14,15 \%)$, refletindo no IAV, com 9,19 $\mathrm{m}^{2}$ área verde/hab.

O setor censitário $\mathrm{n}^{0} 14$ é formado por uma porção do Bairro Alto da Cruz, e os setores de $\mathrm{n}^{\circ} 38$ e 39, ambos situados no Bairro Vila Itacolomi, merecem atenção especial, pois têm os piores valores de DP, PAV e IAV, devendo, portanto o munícipio intensificar a fiscalização quanto ao uso do solo e planejar melhor o crescimento futuro, uma vez que nele estão os dois setores censitários com os piores valores de DP, PAV e IAV.
Pela interpretação dos indicadores pode-se observar que os setores censitários que têm os piores valores de DP, PAV e IAV são os de $n^{\circ}$ 14, 30, 38 e 39, que estão inseridos nos bairros Alto da Cruz, Vila Itacolomi e São Cristovão, portanto os mais críticos da cidade.

Pode-se observar que esses índices tendem para o mesmo resultado, uma vez que em todos é considerada a população, mesmo no PAV, que não considera a população diretamente, mas considera a quantidade de áreas construídas e arruamentos em seu cálculo.

O IAV pode ser importante indicador para guiar o “re”planejamento urbano, informando as áreas altamente antropizadas e acusando o equilíbrio ou desequilíbrio quanto à ocupação dos setores censitários e bairros de uma cidade. De acordo com Jesus \& Braga (2005), os índices de qualidade ambiental relatam as condições do ambiente, estabelecendo metas que se desejam alcançar, avaliando variações temporais a partir de um valor inicial, devendo o IAV ser calculado para cada categoria, por identificar sua suficiência ou escassez.

\section{CONCLUSÃO}

O cálculo da população, DP, PAV e IAV pode ser considerada como mais uma ferramenta para guiar o planejamento ou "re"planejamento urbano, indicando áreas altamente povoadas ou áreas com pouco verde remanescente.

O IAV se mostra eficiente para apresentar as condições ambientais e da população local, principalmente para os setores censitários, porém a falta de consenso científico em relação ao termo "áreas verdes” e a falta de critérios para a sua categorização prejudicam as comparações com os IAV obtidos em diferentes áreas urbanas.

Espera-se, pois, que os resultados desta pesquisa possam ser efetivamente utilizados pelo Poder Público municipal, estadual e federal, nas deliberações quanto ao planejamento urbano.

\section{AGRADECIMENTOS}


Ao Programa de Mestrado em Engenharia Ambiental - PROAGUA/UFOP e CNPq/Capes pelo apoio financeiro, e à Secretária do Patrimônio de Ouro Preto e Instituto Brasileiro de Geografia e Estatística (IBGE) pelos dados cedidos para realização deste estudo.

\section{REFERÊNCIAS BIBLIOGRÁFICAS}

ANDRADE, R. V. O processo de produção dos parques e bosques públicos de Curitiba. Dissertação (Mestrado em Geografia). Setor de Ciências da Terra, Universidade Federal do Paraná, Curitiba, 127p. 2001.

BUCCHERI FILHO, I. A. T.; NUCCI, J. C. Espaços livres, áreas verdes e cobertura vegetal no bairro alto da XV, Curitiba/PR, Revista do Departamento de Geografia, nº18, p 48-59, 2006.

CAPORUSSO, D. \& MATIAS, L. F. Áreas verdes urbanas: avaliação e proposta conceitual. In: $1^{\circ}$ Simpósio de Pós-Graduação em Geografia do Estado de São Paulo. SIMPGEO-SP. VIII SEMINÁRIO DE PÓS-GRADUAÇÃO EM GEOGRAFIA DA UNESP - Rio Claro, SP. Anais... Campus Bela Vista UNESP. 17-19 de novembro de 2008.

CARVALHO, L. M. Áreas verdes da cidade de Lavras/MG: caracterização, usos e necessidades. Dissertação (Mestrado) - Universidade Federal de Lavras. 115 p.2001.

CAStro, J. M. G. Pluviosidade e movimentos de massa nas encostas de Ouro Preto. Dissertação (Mestrado em Engenharia Civil), Universidade Federal de Ouro Preto - UFOP, 114p. 2006.

CAVALHEIRO, F. \& DEL PICCHIA, P. C. D. Áreas Verdes: Conceitos, objetivos e diretrizes para o planejamento. In: CONGRESSO BRASILEIRO SOBRE ARBORIZAÇÃO URBANA, 1, 1992. Anais... p. 29-38, Vitória - ES, 1992.

CAVALHEIRO, F.,NUCCI, J.C.; GUZZO, P.; ROCHA, Y.T. Proposição de terminologia para o verde urbano. Boletim Informativo. Rio de Janeiro: Sociedade Brasileira de Arborização Urbana - SBAU, ano VII, n.3, jul/ago/set-1999, p.7.

DALCIN, E. Arborização de vias públicas. Rio de Janeiro: Light, 2000.

HARDER, I. C. F.; RIBEIRO, R. C. S. \& TAVARES, A. R. Índices de área verde e cobertura vegetal para as praças do município de Vinhedo, SP. Revista Árvore, v.30, n.2: 277-282. 2006.

DI FIDIO, M. Architettura del paesaggio. 3.ed. Milano: Pirola Editores, 1990.

GREY, G. W.; DENEKE, F. J. Urban forestry. New York: Jhon Wiley, 1978.

GUZZO, P. Estudos dos espaços livres de uso público e da cobertura vegetal em área urbana da cidade de Ribeirão Preto, SP. 106 pág. Dissertação (Mestrado em Geociências). Instituto de Geociências e Ciências Exatas, Universidade Estadual Paulista, Rio Claro. 1999.

HENKE-OLIVEIRA, C. Planejamento ambiental da cidade de São Carlos (SP) com

ênfase nas áreas públicas e áreas verdes: diagnósticos e propostas. Dissertação (Mestrado em Ecologia) - Universidade Federal de São Carlos. UFSCAR, São Carlos, 181p. 1996.

IBGE- INSTITUTO BRASILEIRO DE GEOGRAFIA E ESTATÍSTICA. Censo demográfico 2007. Disponível em: <http://www.ibge.gov.br/cidadesat/topwindow.htm Acessado em Novembro de 2010.

IBGE - INSTITUTO BRASILEIRO DE GEOGRAFIA E ESTATÍSTICA. Censo Demográfico 2010. Disponível em: http://www.ibge.gov.br/cidadesat/topwindow.htm?

ÍNDICE E PERCENTUAL DE ÁREAS VERDES PARA... 
Acessado em Maio de 2011.

JESUS, S. C. \& BRAGA, R. Analise espacial das áreas verdes urbanas da estância de Águas de São Pedro - SP. Revista Caminhos da Geografia 18 (16) 207 - 224. 2005.

LIMA NETO, E.M.; RESENDE, W.X.; SENA, M.G.D.; SOUZA, R.M. Análise das áreas verdes das praças do bairro centro e principais avenidas da cidade de Aracajú-SE. Revista da Sociedade Brasileira de Arborização Urbana, v.2, p.17-33, 2007.

LIMA, A. M. L. P. Análise da arborização viária na área central e em seu entorno.

1993. 238f. Tese (Doutorado em Fitotecnia - USP) - Escola Superior de Agronomia “Luiz de Queiroz”, Piracicaba, 1993.

LLARDENT, L. R. A. Zonas verdes y espaços livres en la ciudad. Madrid: Closas. Orcoyen, 1982.

LOMBARDO, M. A. Ilha de calor nas metrópoles. São Paulo: Hucitec, 1985.

LUCON, T. N. Análise espacial das áreas verdes do perímetro urbano de Ouro Preto (MG). Dissertação (Mestrado) - Universidade Federal de Ouro Preto. Instituto de Ciências Exatas e Biológicas. Programa de Pós-Graduação em Engenharia Ambiental. 169 f. 2011.

MATIAS, L. F.; CARVALHO, J.C.B.; MARGUTI, B.O.; FARIAS, F.O. Mapeamento do uso da terra na cidade de Paulínia (SP): desenvolvimento de aspectos metodológicos para detalhamento intra-urbano. Anais... XV ENCONTRO NACIONAL DE GEÓGRAFOS, São Paulo, 2008.

MILANO, M. S. Planejamento da arborização urbana: relação entre áreas verdes e ruas arborizadas. In: ENCONTRO BRASILEIRO SOBRE ARBORIZAÇÃO URBANA, 4, 1990. Curitiba. Anais... Curitiba: Sociedade Brasileira de Arborização Urbana, 1990.

MILANO, M. S. A cidade, os espaços abertos e a vegetação. In: CONGRESSO BRASILEIRO SOBRE ARBORIZAÇÃO URBANA, 1, 1992. Vitória. Anais... Vitória: Sociedade Brasileira de Arborização Urbana, p.3-13. 1992.

MILANO, M. S. Arborização urbana: Plano Diretor. In: CONGRESSO BRASILEIRO SOBRE ARBORIZAÇÃO URBANA, 2, 1994. São Luis. Anais... São Luis: Sociedade Brasileira de Arborização Urbana, 613p. p.207-215. 1994.

MILANO, M. S. Arborização urbana. Curitiba: UFPr, Apostila. 1995.

OLIVEIRA, C.H.; SANTOS, J.E. ; PIRES, J.S.R. Indicadores de arborização urbana da cidade de São Carlos (SP) com o uso do SIG-IDRISI. Brazilian Journal of Ecology, ano 03, n.1, p. 01-09. 1999.

SOBREIRA F. G. e FONSECA M. A. Impactos físicos e sociais de antigas atividades de mineração em Ouro Preto, Brasil. Geotecnia, 92, p. 5-28. 2001.

SOCIEDADE BRASILEIRA DE ARBORIZAÇÃO URBANA - SBAU. “Carta a Londrina e Ibiporã”. Boletim Informativo, v.3, n.5, p.3, 1996.

ZANIN, E. M.; ROSSET, F.; DALAVALE, L. C. Índice de áreas verdes públicas para o município de Getúlio Vargas, RS. In: Anais do VIII Congresso de Ecologia do Brasil. Caxambu, MG. 23 a 28 de Setembro de 2007.

Thiago Nogueira Lucon -Avenida das Andorinhas no 177 i - Morro São João - Ouro Preto - Minas Gerais - Brasil. - Thiago_lucon@hotmail.com 